\title{
LA DESAPARICIÓN DE LAS DIOSAS COMO METÁFORA DE LA PÉRDIDA DE AUTORIDAD DE LAS MUJERES
}

\author{
ANA DOlORES Verdú DELGADO \\ Universidad Nacional de Educación a Distancia
}

Recibido 06/07/2012

Aceptado 08/10/2012

\section{Resumen}

La ausencia de referencias religiosas femeninas vinculadas con el poder no es un fenómeno casual en la historia de la humanidad. La desaparición de los símbolos centrados en la Diosa Madre, así como su estigmatización, forma parte de los mecanismos sociales que aseguraron la estabilidad y reproducción de un orden social que negaba la autoridad a las mujeres. Particularmente en el contexto occidental, la consolidación de un sistema de creencias androcéntrico y sexista ha actuado históricamente como base ideológica del patriarcado, suponiendo la progresiva destrucción de los símbolos femeninos prepatriarcales. En la actualidad, la recuperación de estos símbolos representa un acto de reafirmación de la espiritualidad femenina, así como un cuestionamiento de los valores que nos definen como civilización.

Palabras clave: diosas, poder, teología feminista, espiritualidad femenina

\begin{abstract}
The lack of feminine religious references linked to power is not an accidental phenomenon in human history. The disappearance of the symbols centered on the Mother Goddess, and its stigmatization, are part of the social mechanisms that assured the stability and reproduction of a social order that denied authority to women. Particularly in Western context, the consolidation of an androcentric and sexist system has historically acted as an ideological basis for patriarchy, causing the progressive destruction of pre-patriarchal feminine symbols. At present, the recovery of these symbols represents an act of reaffirmation of women's spirituality, as well as a questioning of the values that define us as a civilization.
\end{abstract}

Key words: goddesses, power, feminist theology, feminine spirituality. 

Una diosa no podía ser esclavizada ni relegada a un papel secundario y oculto, limitado a la procreación y el cuidado de los hijos y las hijas nacidas de la unión con un hombre. De alguna manera la mujer hubo de dejar de ser diosa.

Miguel Lorente ${ }^{1}$

\section{La relación entre símbolos religiosos y organización social ${ }^{2}$}

La ausencia de símbolos religiosos femeninos vinculados con el poder no es un fenómeno casual en la historia de la humanidad. Particularmente en el contexto occidental, la consolidación de un sistema de creencias androcéntrico y sexista ha actuado históricamente como base ideológica del patriarcado, suponiendo la progresiva destrucción de los símbolos femeninos prepatriarcales, y garantizando la estabilidad de unas estructuras sociales que excluían a la población femenina de toda fuente de poder. Desde esta perspectiva, los valores que un determinado sistema simbólico proyecta como positivos no son independientes de los intereses propios del contexto social donde se producen, por lo que en la realidad humana las coincidencias entre las dimensiones material y simbólica tenderán a mantener una lógica estructural.

Esta complejidad característica de los fenómenos sociales, derivada de la simultaneidad en que lo material y lo simbólico se expresan en la dependencia entre hecho y sentido, realidad e interpretación, ha obligado a las disciplinas sociales a emplear modelos de análisis capaces de integrar la interacción de sus diferentes dimensiones. La teoría explicativa de la subordinación social de las mujeres es un ejemplo de cómo lo simbólico puede llegar a expresar los intereses de los grupos poderosos, convirtiéndose en garantía de perpetuación de un sistema. Para Bourdieu, la historia de la dominación en la vida humana no puede estudiarse sin abarcar los elementos culturales que han facilitado a

1. LORENTE, Miguel. Los nuevos hombres nuevos. Los miedos de siempre en tiempos de igualdad. Barcelona. Destino, 2009, p. 27.

2. Este artículo surge como resultado del trabajo de investigación realizado por la autora para el diseño de la asignatura "Las mujeres en la historia», impartida en los cursos 2010/2011 y 2011/2012 en los centros asociados de la UNED de Elda y Elche, dentro del programa de la Universidad Abierta. 
través de referentes símbolos la adecuación del individuo a las expectativas sociales, lo que puede conllevar incluso la participación de la persona en su propia subordinación ${ }^{3}$. La violencia simbólica surge así como mecanismo de producción y reproducción del poder que conduce a la interiorización de los valores del grupo dominador en la propia identidad del individuo dominado, convirtiendo además lo que es en teoría una realidad arbitraria (cultural) en natural, por manifestarse desde la propia subjetividad ${ }^{4}$.

Desde esta perspectiva, las relaciones sociales que implican cierto grado de dominación de un grupo por otro aparecen asociadas irremediablemente a ideologías discriminatorias que normalizarían y naturalizarían la inferiorización del colectivo subordinado, garantizando la reproducción de un sistema injusto y minimizando el uso de la fuerza. Así, las representaciones simbólicas de las mujeres y de los hombres en el contexto de las sociedades patriarcales no son simples imágenes que funcionan aisladas de una realidad social, sino que se convierten en metáforas de los géneros, dictando las funciones posibles de cada uno en una sociedad determinada.

Entre este conjunto de símbolos, los religiosos adquieren una importancia clave por su capacidad para representar un poder que los seres humanos han interpretado como divino, e integrado en un orden natural e incuestionable. Peggy Reeves lo explica de la siguiente manera:

Las historias sobre la creación nos dicen algo acerca de cómo la gente concibe la naturaleza y el origen del poder creador. Los actores principales en estas historias pueden ser interpretados como metáforas de antiguas pero aún posibles identidades sexuales. También el hecho de que el creador sea concebido en términos masculinos o femeninos tiene consecuencias importantes para la evolución de la relación de autoridad entre los sexos. A fin de entender el poder femenino y el dominio masculino, es importante poner en claro desde el principio la interconexión entre poder sobrenatural y planificación sexual ${ }^{5}$.

El lenguaje, los mitos, los cultos y tradiciones se configuran desde el análisis simbólico como códigos y guías de conducta necesarios para el ordenamiento de la vida social, lo que a su vez pone de relieve la estrecha conexión, siguiendo a Gerda Lerner, entre las definiciones del género y la formación del estado ${ }^{6}$.

El sexo se convierte así en una cuestión política, ya que del significado que se le asigne podrá inferirse una determinada estructura de poder. De esta

3. Bourdieu, Pierre. La dominación masculina. Barcelona. Anagrama, 2000, pp. 11-21.

4. Bourdieu, Pierre. Op. cit., p. 21.

5. REEVES SANDAY, Peggy. «Escritos para el poder femenino», en Aurora Marquina (comp.). El ayer y el hoy: Lecturas de antropología política. Volumen I. hacia el futuro. Madrid. Universidad de Educación a Distancia, 2004, p. 314.

6. LERNER, Gerda. La creación del patriarcado. Barcelona. Crítica, 1990, p. 310. 
manera, la estabilidad de un sistema con reparto de poder en función del sexo irá unida irremediablemente a un esquema de género que lo legitime. Como indica Reeves, «a partir de las proposiciones con las que un pueblo codifica su identidad social y religiosa podemos inferir el plan históricamente aprobado que estructura las relaciones entre los sexos ${ }^{7}$. La antropóloga plantea la existencia de una coherencia ideológica entre símbolos religiosos y organización social al analizar algunos mitos sobre la creación de diversas culturas, comprobando la relación existente entre un mayor protagonismo femenino en los símbolos religiosos y la mejor posición social de las mujeres con respecto a las sociedades en las que la creación es un acto asignado a un único Dios masculino. Entre la variedad de simbolismos representativos de las diferentes culturas, Reeves pone como ejemplo el politeísmo de los semang, pueblo nómada de la península Malaya, en el que se integran los principios femenino y masculino en una deidad femenina y otra masculina. La Diosa para este pueblo, asimilada a la Madre Tierra, tendría el papel central en la creación, siendo además intercesora de los poderes masculinos, representados por el trueno y la tormenta. La relativa igualdad en las representaciones míticas de esta sociedad se da paralelamente a una organización social que, aunque integra cierta división sexual del trabajo, permite la participación de hombres y mujeres en las actividades cotidianas y la igualdad en los derechos de propiedad y en la toma de decisiones ${ }^{8}$. Un ejemplo diferente lo compone el caso de los iroqueses, pueblo originalmente matriarcal cuyo mito fundacional pondría más énfasis en el principio femenino9.

El predominio de una interpretación de la creación ligada a valores femeninos es también común cuando se hace referencia a las etapas prehistóricas. Son numerosos los trabajos históricos y antropológicos que analizan el significado de las estatuillas prehistóricas femeninas conocidas con el nombre de Venus, «quizá porque son las representaciones humanas más antiguas y más abundantes, aparecidas hace más de 30.000 años» ${ }^{10}$. Cristina Masvidal relaciona la existencia de estatuillas femeninas con notables coincidencias desde los Pirineos hasta Siberia con dos posibles hechos: 1) la creencia en una gran Diosa Madre, posiblemente traída por los humanos modernos llegados de África, y 2) el protagonismo femenino en la vida social en estas etapas,

7. ReEVes Sanday, Peggy. Op. cit., p. 313.

8. Ibíd., pp. 317-320.

9. Ibíd., pp. 323-327.

10. MASVIDAL, Cristina. «La imagen de las mujeres en la prehistoria a través de las figuritas femeninas paleolíticas y neolíticas», en VV.AA. Las mujeres en la prehistoria. Valencia. Diputació Provincial de València. Museu de Prehistòria de València, 2006, p. 39. 
teniendo en cuenta que la imagen femenina también puede ser representativa de la humanidad o del grupo, en cuyo seno la mujer sería la encargada de asegurar la renovación y la subsistencia de la especie a través de la maternidad ${ }^{11}$.

También Yadira Calvo, buscando el significado profundo de la simbología prepatriarcal, analiza la existencia documentada de divinidades femeninas que se remontan a la prehistoria para entender los valores matricéntricos que debieron predominar en gran parte de la existencia humana, antes de que los símbolos de poder femenino fueran destruidos o demonizados.

La Diosa Triple o Diosa Madre, o Gran Diosa de la Vida, la Muerte y la Regeneración, era una divinidad lunar, imagen central de la religión neolítica de la Vieja Europa, que aparece en tres formas: una joven, una madre, una anciana, que representan respectivamente sus aspectos de Creadora, Protectora y Destructora ${ }^{12}$.

El hecho de que estas representaciones culturales contengan una idealización de lo femenino vinculada al poder de la creación ha hecho pensar la prehistoria como contexto en el que las mujeres debían disfrutar de un estatus importante, incluso superior al de los hombres. Este poder se acentuaría con el desconocimiento de la paternidad, que haría aparecer a la mujer como única creadora de vida y «dueña» legítima de la descendencia del grupo ${ }^{13}$. Sobre esta suposición Lorenzo Mediano desarrolla una apasionante historia en su novela El secreto de la diosa, que sitúa en el inicio del Neolítico. La novela de Mediano recrea los acontecimientos y cambios sociales que pudieron producir el inicio de un patriarcado, o al menos, las bases para su futuro desarrollo. Junto a la fuerza de las redes masculinas resultante del aumento de las guerras, el descubrimiento de la paternidad (y su representación a través de nuevos símbolos/dioses) vertebra una trama que lleva al fin de la autoridad social de las mujeres.

El secreto de la diosa nos sitúa en un periodo prehistórico en el que la capacidad para producir la vida, poder específico de las diosas/es, podía constituir un elemento clave para definir la superioridad del estatus de un individuo. Sin embargo, la vinculación de este poder vida con la esencia masculina

11. MASvidal, Cristina. Op. cit., pp. 37-50.

12. Calvo, Yadira. La canción olvidada. Heredia (Costa Rica). EUNA, 2002, p. 162.

13. La discusión sobre la responsabilidad masculina y femenina en el acto de reproducción de la vida ha estado, de hecho, presente en diferentes discursos construidos desde la defensa o la crítica de la estructura asimétrica de poder que afecta a los sexos. Pongo como ejemplo la defensa de Aristóteles del patriarcado a partir de la superioridad masculina «demostrada» en la prevalencia del principio masculino en la procreación, o la crítica de Agrippa, defensor de la igualdad entre hombres y mujeres, del dominio masculino, argumentando, entre otros aspectos, la mayor responsabilidad femenina en este mismo acto. 
en un contexto de predominio de la naturaleza, en el que existía una unión patente entre la mujer y la vida, lo femenino y lo sagrado, debió suponer un giro radical del orden simbólico que necesitaría un cambio profundo de los significados antiguos, así como miles de años para imponerse como realidad normativa. Este cambio implicaba, como refleja Mediano en su novela, la destrucción del poder de la Diosa, y su atribución a los dioses masculinos.

Destruido el poder de la Diosa, los dioses masculinos dominaron el mundo. La paciente conspiración había triunfado. A partir de ese momento, el cielo, la tierra y el infierno serían regidos por dioses varones. Incluso tomaron el atributo de eternos y sus adoradores afirmaban que no los había parido ninguna diosa madre. Sin embargo, las diosas sobrevivieron. Como predijera Mara un día, hasta los más fieros guerreros necesitaban en ocasiones del consuelo de las divinidades femeninas. Pero ahora eran diosas sometidas, de poder débil y poco eficaz, que sólo podían interceder antes los verdaderos amos: los dioses masculinos. Los dioses, como los varones, fueron omnipotentes ${ }^{14}$.

En el proceso de estructuración de la organización patriarcal tuvo, por tanto, un papel fundamental la difusión de una simbología androcéntrica integradora de una ideología que asignaba el poder creativo de la vida a un Dios varón y que, en consecuencia, proclamaba la preeminencia de los hombres sobre las mujeres en el plano social. Entre los trabajos antropológicos que documentan este hecho se encuentra el de Godelier ${ }^{15}$ sobre el dominio masculino entre los Baruya de Nueva Guinea. Godelier relaciona la historia mítica fundacional de los Baruya, en la que se asigna un papel positivo a lo masculino y negativo a lo femenino, con la necesidad de este pueblo de justificar la dominación masculina sobre las mujeres. El antropólogo alude a la utilidad que tendría para el mantenimiento del orden patriarcal de los Baruya la denigración del poder creativo femenino y su expropiación, al ser reasignado a los hombres, como medios complementarios de someter a las mujeres. Los vestigios de un antiguo poder maternal encontrados en la interpretación negativa del poder femenino llevarían a Godelier a señalar la eliminación de la madre, paralelamente a la magnificación del padre y de lo masculino, como elemento clave de la violencia simbólica que actuaría sobre las mujeres Baruya legitimando el poder de los hombres en la sociedad ${ }^{16}$.

La sustitución del orden de la madre por el orden del padre constituye además un fenómeno trascendental en la propia historia de la humanidad, que va

14. MEDIANO, Lorenzo. Op. cit., p. 451.

15. Godelier, Maurice. La producción de Grandes Hombres. Poder y dominación masculina entre los Baruya de Nueva Guinea. Madrid. Akal, 1986.

16. GODELIER, Maurice. Op. cit., pp. 84-85.

Feminismo/s 20, diciembre 2012, pp. 63-80 
más allá de su expresión en una determinada cultura, puesto que la maternidad es un hecho natural que afecta a toda vida humana. De ahí que algunos trabajos hayan relacionado este fenómeno con el paso de un tipo de sociedad ligada a la naturaleza a otra gobernada por leyes masculinas que habrían producido como resultado el distanciamiento humano con respecto a una gran parte de su realidad natural. Según Luce Irigaray, «al abolir las genealogías femeninas y con ellas el respeto a la tierra y al universo material, las civilizaciones patriarcales han inhibido una parte de la realidad social ${ }^{17}$, haciendo depender el significado de las cosas de las creencias, más que de la lógica real de los acontecimientos.

Por otro lado, la existencia de documentos históricos de culturas antiguas que contienen una interpretación de lo femenino unida al poder, fundamentalmente relacionada con la capacidad de crear y sustentar la vida, ha llevado incluso a la elaboración de hipótesis sobre la posible existencia de una sociedad matriarcal anterior al patriarcado. Desde la antropología, Bachofen, aunque interpreta la sustitución de un derecho natural por el derecho civil patriarcal como forma de progreso en un contexto específico, defiende la existencia de un periodo de la historia de la humanidad en el que los valores morales, jurídicos y políticos habrían estado estructurados en torno a la idea de la mujer y la madre ${ }^{18}$.

Sin embargo, el debate sobre el matriarcado es complejo ya que, aun admitiendo que las primeras sociedades se organizaron generalmente de modo matrilineal y/o matrifocal y las mujeres tuvieron un protagonismo incuestionable en la vida social, no se ha comprobado que ejercieran nunca un control sobre los hombres comparable al que los hombres ejercerían sobre las mujeres dentro de la organización patriarcal, por lo que no sería correcto emplear la palabra matriarcado con la connotación de dominio/ jerarquía propia del significado de patriarcado. Cuando además hablamos de sociedades primitivas, entendemos que el dominio de unos grupos sobre otros se presenta menos estructurado que en las sociedades complejas, lo que hace que en términos de poder político sean categorizadas a menudo como «sociedades igualitarias» ${ }^{19}$.

A esto hay que añadir que el dominio masculino sobre las mujeres ha constituido a su vez un fenómeno social unido en cierta medida a la fuerza. Los análisis históricos sitúan de hecho la pérdida de poder de las mujeres y de importancia de las diosas en un contexto social en el que se incrementan los enfrentamientos bélicos y el control de las armas por parte de los hombres.

17. IRIGARAY, Luce. Yo, tú, nosotras. Madrid. Cátedra, 1992, p. 25.

18. BACHOFEN, Johann Jacob. El matriarcado. Una investigación sobre la ginecocracia en el mundo antiguo según su naturaleza religiosa y jurídica. Madrid. Akal, 1992.

19. LeWelen, Ted C. Introducción a la Antropología Política. Barcelona. Bellaterra, 1994, p. 39. 
Las guerras garantizarían el poder de los hombres, tanto en el acceso a los recursos como en el plano simbólico, ya que justificaría el ensalzamiento de los valores masculinos y la preferencia de los dioses frente a las diosas ${ }^{20}$. Es decir, la destrucción del poder de las mujeres como creadoras de vida debió producirse paralelamente a la glorificación del poder de dar muerte, y a medida que este poder se hacía más central para la supervivencia del grupo, con más contundencia parecían eliminarse los antiguos símbolos del poder femenino.

El ataque simbólico a las cualidades naturales y «mágicas» de las mujeres se iniciaría posiblemente en la Edad de Bronce (hace entre 6.000 y 5.000 años), coincidiendo con el aumento de la violencia y con una conciencia ya adquirida del dominio sobre la naturaleza, fenómenos que facilitarían la utilización por parte de los hombres de las capacidades reproductoras de las mujeres con el fin de consolidar el modelo patriarcal ${ }^{21}$. También se sitúa en esta época la militarización de las diosas, como la Atenea griega o las irlandesas Morrigan y Badb, que empezarían a asociarse con la guerra ${ }^{22}$. No obstante, la violencia no se considera en sí misma un mecanismo capaz de mantener indefinidamente un nuevo orden social. La sociedad patriarcal, para garantizar la destrucción del poder de las mujeres, hubo de crear estructuras de sentido en las que lo femenino apareciera ya subordinado, o vinculado a cualidades negativas ${ }^{23}$.

En definitiva, parece probado que en la historia de las mujeres la destrucción y la devaluación de los símbolos religiosos femeninos han actuado de forma correlativa con su subordinación social. Como señala Lerner, «la hegemonía masculina dentro del sistema de símbolos fue lo que situó de forma decisiva a las mujeres en una posición desventajosa ${ }^{24}$. En el triunfo y mantenimiento de esta hegemonía Lerner destaca, junto con la privación de educación a las mujeres, el monopolio masculino de las definiciones, que inicialmente hubo de legitimarse mediante la apropiación y transformación de los principales símbolos de poder femenino, el de la Diosa Madre y el de las diosas de la fertilidad. Este cambio sería transcendental para la redefinición de la existencia femenina a partir de la subordinación y la dependencia con respecto al varón ${ }^{25}$, y por supuesto, arrastraría implicaciones importantes en la condición moral de las mujeres.

20. LERNER, Gerda. Op. cit., pp. 63-89.

21. LORENTE, Miguel. Los nuevos hombres nuevos. Los miedos de siempre en tiempos de igualdad. Barcelona. Destino, 2009, pp. 26-27.

22. CAlvo, Yadira. Op. cit., 48.

23. LORENTE, Miguel. Op. cit., p. 27.

24. LERNER, Gerda. Op. cit., p. 319.

25. Ibíd., p. 319.

Feminismo/s 20, diciembre 2012, pp. 63-80 


\section{Monoteísmo masculino y autoridad moral de las mujeres}

La historia de la religión en el contexto occidental sel desarrolla a partir de un esquema propio de las sociedades patriarcales, notando que, desde la extensión del monoteísmo masculino, la interpretación de lo divino ha evolucionado en nuestra cultura hacia la negación e invisibilización de lo femenino en el plano de lo sagrado. Reeves relaciona la transición en el pueblo israelita del politeísmo hacia un monoteísmo masculino, centrado en el culto a Yavhé, con la ascendencia política de Moisés y la emigración de los hebreos desde Egipto, señalando el hecho de que durante siglos las diosas se mantuvieron sin conflictos importantes, asignándoles funciones distintas de las asignadas a los dioses masculinos ${ }^{26}$.

Según Reeves, la dificultad para erradicar el culto a las diosas aparece en el Génesis mediante metáforas que simbolizarían la censura del poder femenino como modo de resolver el conflicto entre la adoración a Yavhé y el mantenimiento del culto a las diosas canaitas Aserah y Anath ${ }^{27}$. Su trabajo antropológico apunta a que el árbol de la ciencia del bien y del mal, del que Dios prohíbe comer, simboliza a la Diosa Asherah pues a ella se le atribuía la unión del bien y el mal y sus lugares de culto eran señalados con árboles. Su tesis sugiere que las metáforas del Génesis pueden ser interpretadas como la prohibición de aceptar los símbolos de poder femenino.

También la mitología griega contiene ejemplos de censura del poder femenino. En este contexto, son numerosas las figuras femeninas con deseo de poder y autonomía utilizadas como modelo de maldad y perversión, que acaban bajo el dominio legítimo y ordenado de un Dios masculino. El asesinato de Orestes a su madre Clitemnestra, ejemplo de la rebeldía femenina con respecto al orden masculino, es defendido por el Dios Apolo y la Diosa Atenea en la obra de Esquilo, y se convierte así en símbolo de la primacía del derecho paterno sobre el materno ${ }^{28}$.

Por otro lado, la inferiorización de la mujer en la religión dentro de la historia de Occidente ha ido de la mano de una asociación simbólica de lo femenino con la lascivia y el pecado, lo que se manifiesta paralelamente al

26. Reeves Sanday, Peggy. Op. cit., pp. 337-338.

27. «Puedes comer del fruto de todos los árboles del paraíso. Mas del fruto del árbol de la ciencia del bien y del mal no comas; porque en cualquier día que comieres de él, ciertamente morirás» (Génesis 2, 16-17), citado en REEVES SANDAY, Peggy. Op. cit., p. 342.

28. RodríGUEz BlanCo, María Eugenia. «Mujeres monstruo o monstruos de mujer en la mitología griega», en Rosario López Gregorio y Luis Unceta Gómez (eds.). Ideas de mujer. Facetas de lo femenino en la Antigüedad. Centro de Estudios sobre la Mujer de la Universidad de Alicante, 2011, pp. 81-83. 
desarrollo de un esquema de género que a lo largo de los siglos ha asignado la autoridad intelectual, moral y política a los hombres a la vez que ha extendido una imagen de las mujeres de carácter esencialmente sexual. En la difusión de este esquema tuvo un papel importante el triunfo del modelo cristiano ortodoxo, frente al gnóstico, a partir de la aprobación del cristianismo como religión oficial en el siglo IV ${ }^{29}$.

La cristianización de Europa da el monopolio de los medios de producción cultural a la iglesia, que radicaliza la manipulación de las imágenes femeninas, asociándolas a la inferioridad moral. Calvo pone como ejemplo la figura de Morgana por considerarla representativa de cómo la cristianización de las Islas Británicas influyó en una reinterpretación de las hadas, espíritus matriarcales que vivían en el reino de la Diosa, convirtiéndolas en seres malos y pernicio$\operatorname{sos}^{30}$. En general, el monoteísmo masculino se ha dado con un gran esfuerzo ideológico no libre del uso de la fuerza. Sin embargo, su coherencia con un contexto social de dominio de lo masculino sobre lo femenino ha hecho posible su interiorización como realidad natural para una gran mayoría de personas.
La idea de una diosa creadora fue anatemizada por los teólogos cristianos, y mucho antes por los teólogos judíos. La mayoría de los científicos, por con- veniencia social, adoran a un Dios; aunque no puedo comprender por qué la creencia en un Dios Padre como autor del universo y de sus leyes parece menos anticientífica que la creencia en una Diosa Madre inspiradora de este sistema artificial $^{31}$.

Como ya se ha visto, el triunfo del monoteísmo masculino necesitó extender un significado negativo de la feminidad, en particular, de la feminidad ligada a cualquier tipo de poder. Las divinidades femeninas, así como la función ancestral de las mujeres en los ritos religiosos, dejaron de ser símbolos de la autoridad moral de las mujeres para convertirse en pruebas de «brujería», «hechicería», «paganismo», «herejía» y manifestaciones del mal. Luis Unceta hace alusión a esta feminización de la magia, que quedaría asociada con el peligro y la subversión de los papeles de género ${ }^{32}$, representando la no legitimación social del poder femenino.

La caza de brujas llevada a cabo por la iglesia es, de hecho, un episodio clave desde la teología feminista y la historia de las mujeres, para entender

29. Ibíd., pp. 345-350.

30. Calvo, Yadira. Op. cit., p. 43-46.

31. Ibíd., p. 35.

32. UNCETA GÓMEZ, Luis. «De profesión, maga», en Rosario López Gregorio y Luis Unceta Gómez (eds.). Ideas de mujer. Facetas de lo femenino en la Antigüedad. Centro de Estudios sobre la Mujer de la Universidad de Alicante, 2011, p. 321. 
las dificultades que plantea un monoteísmo masculino construido desde la oposición de los géneros y su esencialización. Teresa Forcades explica que el apogeo de la quema de brujas coincidiría con el advenimiento de la modernidad y la crisis de autoridad eclesiástica propiciada por la extensión de valores humanistas, aunque también incide en la importancia que tuvo la difusión de ideología misógina por parte de la iglesia. Como ejemplo consta la obra de los inquisidores dominicos Institoris y Sprenger Malleus Maleficarum «El Martillo de las brujas», de la que resalta la demonización de las mujeres que pretenden desarrollar su capacidad intelectual y manifestar un pensamiento propio ${ }^{33}$.

El uso de los sistemas de creencias para la justificación de un tratamiento discriminatorio del conjunto de la población femenina ha hecho que a lo largo de la historia surgieran voces críticas hacia la misoginia de los postulados filosóficos y teológicos. Desde la propia religión católica, el esfuerzo por otorgar dignidad y espiritualidad a la figura femenina ha formado parte de muchos discursos de religiosas, entre las que se puede destacar a Santa Teresa de Jesús, a Isabel de Villena y a Juana Inés de la Cruz, por su ejercicio personal de autonomía moral/intelectual, así como por su trabajo literario dedicado a la exaltación de los valores femeninos ${ }^{34}$. También desde el primer sufragismo norteamericano la reivindicación de la igualdad entre hombres y mujeres en cuanto a esencia moral llevó a reflexiones teológicas que desvelaban el carácter político, y no religioso, de los intereses que imperaban en las interpretaciones sexistas de los textos sagrados. Como obra representativa de este pensamiento quedó The Women's Bible, de Elizabeth Cady Stanton ${ }^{35}$.

Pero es en el siglo XX cuando aparece como corriente de la teología crítica un pensamiento claramente feminista que desvela que la esencialización de los sexos no sólo forma parte de las estructuras socioeconómicas y políticas, sino que también vertebra la organización religiosa. En palabras de Forcades, «la teología feminista es una modalidad de teología crítica o de la liberación», pues ofrece alternativas a las contradicciones teológicas que guardan relación con situaciones de discriminación e injusticia ${ }^{36}$. Teniendo en consideración que la mujer ha sido en las doctrinas religiosas objeto importante de reflexión, las teólogas feministas reivindican a las mujeres como sujetos de conocimiento

33. «[...] los autores del Malleus declaran que una de las señales que caracterizan a las mujeres que han sido poseídas por el demonio es que, contra la ley natural y la voluntad de Dios, consiguen vencer a los varones en una discusión racional», en FORCADES I VILA, Teresa. La teología feminista en la historia. Barcelona. Fragmenta Editorial, 2011, p. 60.

34. FORCADES I VILA, Op. cit.

35. GÓmEZ ACEBO, Isabel. «Dios en la teología feminista. Estado de la cuestión», p. 4. Disponible en: http://www.ciudaddemujeres.com/articulos/article.php3?id_article=30

36. ForCADES I VILA, Op. cit., p. 19. 
y de autoridad moral, y de esta forma crean en el seno de la religión un discurso radicalmente diferente al que tradicionalmente prescribía el lugar de la mujer en el mundo a partir de su subordinación, destapando asimismo el sufrimiento real de millones de las mujeres y de su relación con la desigualdad de género.

En opinión de Forcades, la manifestación de este discurso crítico en el contexto del monoteísmo cristiano ha evolucionado a lo largo de la historia desde la reivindicación de la igual dignidad y espiritualidad de las mujeres con respecto a los hombres en las sociedades premodernas, al cuestionamiento en los siglos XIX y XX de las normas que prohíben a las mujeres intervenir plenamente en el ámbito público, tanto en la política como en el sacerdocio, pasando por las reivindicaciones de igualdad en el acceso a la educación en el inicio de la modernidad. La etapa posmoderna estaría caracterizada por la afirmación de la igual capacidad de hombres y mujeres para el amor y el cuidado en el ámbito doméstico ${ }^{37}$.

En definitiva, un gran número de personas reflexionan hoy sobre los problemas que plantea un cristianismo no libre de los valores culturales que a lo largo de la historia han legitimado la discriminación social de las mujeres, y sobre el papel de éste en el mantenimiento y producción de interpretaciones de lo femenino limitadoras que tienden a negar o minimizar la capacidad moral de las mujeres.

\section{Una visión crítica desde la teología feminista y el ecofeminismo}

La preocupación por los sistemas de valores y creencias que incorporan las prácticas de la religión y por su relación con el déficit de autoridad de las mujeres se da en un contexto en el que, aunque la igualdad de género se ha integrado como principio regulador de la convivencia, transformando significativamente muchos aspectos de la estructura social, los referentes simbólicos de lo femenino siguen funcionando dentro de la lógica jerárquica y dicotómica que naturaliza la desigualdad entre los sexos y perpetúa la discriminación de las mujeres como sujetos de conocimiento y autoridad moral.

Contra esta lógica surgen movimientos que reivindican la necesidad de una nueva espiritualidad o de un cambio radical en los valores culturales, que permita deshacer la creencia dualista asentada en el pensamiento occidental a partir de la división artificial entre lo femenino y lo masculino, lo humano y lo natural, el cielo y la tierra, el occidental y el otro.

En la teología feminista, ya en el siglo XX, este interés ha tomado forma, por un lado, en las críticas de los postulados androcéntricos que asumen las

37. Ibíd., pp. 135-136.

Feminismo/s 20, diciembre 2012, pp. 63-80 
interpretaciones (especialmente de la identidad femenina) y prácticas religiosas en el contexto del monoteísmo masculino, denunciando la desigualdad en una simbología que sirve como referente de la moralidad. Defendiendo esta postura, la teóloga Isabel Gómez entiende el hecho de hablar de Dios en términos exclusivamente masculinos como una analogía de la realidad en la que el poder es un valor asignado al varón, y señala que «un Dios descrito como varón se convierte en un varón Dios» ${ }^{38}$. Al mismo tiempo, desde esta corriente se critica que la interiorización para las mujeres de esta «masculinidad divina» bloquearía su capacidad para aportar una comprensión de Dios desde la propia experiencia femenina. Así, teólogas como Rosemary Radford Ruether o Mary Daly asociarían la implícita superioridad de lo masculino en la teología cristiana a las dificultades para mantener un espacio para la espiritualidad femenina ${ }^{39}$.

Y, por otro lado, aparece como segunda gran tendencia dentro de las nuevas corrientes espirituales que conforman la teología feminista la llamada teología de la Diosa, desde la cuál resulta igualmente necesario volver a las raíces religiosas matriarcales y analizar las causas por las que las diosas fueron sustituidas por dioses y las mujeres dejaron de ser sacerdotisas para pasar a representar la imagen principal del pecado ${ }^{40}$. La ausencia de referencias femeninas en las funciones socialmente definidas como sagradas, junto con la existencia de una máxima autoridad masculina representada en la figura de un Dios varón, llega a representar para las teólogas de esta corriente un factor que incentivaría la dependencia psicológica de los hombres por parte de las mujeres, notando además que «una mujer no puede nunca afirmar su plena identidad sexual como algo a imagen y semejanza de Dios» ${ }^{41}$.

Todas estas críticas coinciden en que el tratamiento actual de lo femenino desde el plano religioso actúa como instrumento de censura de la voz femenina y de negación de la capacidad de las mujeres para definir el mundo, para hacer valer los valores propios y no patriarcales, para construirse como sujetos morales, con independencia psicológica y autonomía, y en definitiva, para desarrollar una identidad libre de estereotipos sexuales, a partir de una autoimagen positiva. La posibilidad que ofrecen los símbolos religiosos antiguos basados en el poder femenino, de fomentar la independencia psicológica de las mujeres y la igualdad entre los sexos, hace que el interés por las diosas

38. GÓMEZ ACEBO, Isabel. Op. cit., p. 7.

39. Ibíd., pp. 8-9.

40. Ibíd., pp. 10-14.

41. ReEves SANDAY, Peggy. Op. cit., p. 334. Reeves hace alusión aquí a la visión de Carol Christ sobre el papel central de las estructuras profundas e inconscientes de la mente en la forma en que se manifestarán unos determinados comportamientos o expectativas. 
resurja como parte de una búsqueda femenina de recuperación y validación de los propios valores ${ }^{42}$. La vigencia de este fenómeno en la actualidad proviene de que, si bien lo femenino fue objetivamente disuelto en la comprensión del género (esquema cultural generador de la estricta dicotomía feminidad/ masculinidad), lo cierto es que los sistemas lógicos que actualmente monopolizan las ideas de neutralidad y universalidad siguen siendo los producidos históricamente desde los valores patriarcales. Por este motivo, Ivone Gebara señala la necesidad que presenta la misma humanidad de incorporar la voz femenina en la dimensión religiosa, y de abrirse así a nuevos conceptos de espiritualidad, lo que además implica superar el rechazo del cuerpo femenino que la teología cristiana ha propiciado al tomarlo como símbolo de una sexualidad inextricablemente unida a la idea de pecado.

Es preciso dejar que hable en nosotros la mujer, ese pedazo de la humanidad, ese pedazo de cada ser humano, cuyo concepto va más allá del sexo primero o segundo... Es preciso dejarla hablar a partir de su dolor y, desde ese lugar, abrir puertas de esperanza, sueños, aspiraciones, tiernas pasiones... ${ }^{43}$

De forma general, la teología feminista representa una teología encarnada que, al recuperar lo femenino, recupera también el poder del cuerpo y la vida en la tierra como proyecto divino, y da un sentido concreto al éxtasis y al dolor propios de lo humano. Al mismo tiempo, es una teología centrada en la creación y en el amor como experiencia integral, cotidiana y concreta, de ahí que los símbolos de la Gran Diosa, antiguamente representativos de la fertilidad y el poder sobre la vida, se ajusten a los valores que plantea esta espiritualidad, en mayor medida que los que expresan la omnipotencia y distancia de Dios con respecto a lo humano.

A menudo se hace hincapié en los vínculos que esta espiritualidad mantiene con los principios ecofeministas, puesto que la destrucción de los símbolos de poder femenino coincide con el progresivo distanciamiento del ser humano con la naturaleza y con el triunfo del dominio como elemento central en el sistema de relaciones de género y de los humanos con el mundo natural. La espiritualidad o espiritualismo ecofeminista pondría de manifiesto cómo la cultura occidental ha problematizado simultáneamente lo femenino y lo natural, así como el tratamiento de la alteridad, destapando el paralelismo de la violación de los principios femeninos y de la naturaleza ${ }^{44}$. Gebara coincide con estos planteamientos al aludir a un renacer que implica la vuelta a los

42. Ibíd., p. 349.

43. GEBARA, Ivone. Teología a ritmo de mujer. Madrid. San Pablo, 1995, p. 97.

44. Kramarae, Cheris y SPEnder, Dale (eds.). Espiritualidad de la diosa. Enciclopedia Internacional de las mujeres. Madrid. Síntesis, 2006, pp. 823. 
orígenes y la experiencia de admiración de lo maravilloso de la creación, lo que a su vez nos llevaría a experimentar la connaturalizad con la Tierra.

Hemos olvidado nuestros orígenes... Durante mucho tiempo los fijamos en la imagen masculina de Dios Padre, del Dios creador, del que existe independientemente de la criatura, del que somete a sí todas las cosas. Este no es nuestro origen. Es un producto cultural idealizado a lo largo de siglos de dominación religiosa masculina, que no corresponde a una visión universalista capaz de unir a la humanidad respetando la diferencia de expresión. Por eso hemos de volver a la matriz, a la tierra, y extraer de ella la energía primitiva, condición de toda hermandad ${ }^{45}$.

De forma contraria a los preceptos filosóficos y religiosos de la tradición occidental, en la antigua simbología de la Diosa lo divino y lo natural no constituyen polos opuestos, sino dimensiones de la experiencia humana fundidas en la idea de lo sagrado. Dentro de esta lógica, la mujer no sólo no se configuraría en oposición al hombre o a la naturaleza, sino que su poder para crear vida la convertiría en mediadora entre lo humano y lo divino-natural. Así, será también posible encontrar en la ecología una defensa de los antiguos símbolos religiosos femeninos, haciendo alusión a la interpretación positiva que adquiere en ellos la conexión entre la humanidad y la naturaleza. Para Carolyn Merchant, el sentido de una «ecología espiritual» proviene precisamente de la necesidad de transformar los valores para curar el planeta ${ }^{46}$, un planeta marcado por los estragos del poder, la ambición y el desconocimiento de la realidad natural que sufrimos como efecto del capitalismo patriarcal.

\section{Una nueva espiritualidad desde los valores «femeninos»}

En resumen, la ausencia de referentes simbólicos femeninos ligados al poder, así como la dificultad de hacer valer las propias definiciones femeninas no patriarcales, guardaría relación con un déficit estructural de autoridad de las mujeres que limitaría su capacidad para desarrollar un autoconcepto positivo y libre de las ideas estereotipadas de lo femenino ligadas a la subordinación. La recuperación en este contexto de los símbolos antiguos de poder femenino es coherente con la necesidad expresada por muchas mujeres de autoafirmación y desarrollo de una identidad no reducida ni conflictivizada, pero también de la necesidad de reafirmación y extensión de los propios valores y conocimientos más allá del espacio acotado a lo femenino. Este hecho hace que para Irigaray los mitos religiosos y civiles no representen realidades

45. GEBARA, Ivone. Op. cit., p. 104.

46. Merchant, Carolyn. «Spiritual Ecology», en Carolyn Merchant. Radical Ecology. New Cork. Chapman \& Hall, 1992, pp. 110-131. 
secundarias, sino elementos conectados con el propio bienestar subjetivo, además de mecanismos esenciales para perpetuar el poder.

Ante la estatua que representa a María y a su madre, Ana, me sentí serena y gozosamente instalada en mi cuerpo, en mis afectos, en mi historia de mujer. Tenía ante mí una figura ética y estética que necesito para vivir sin despreciar mi encarnación, la de mi madre y la del resto de las mujeres ${ }^{47}$.

En tiempos de igualdad formal y de democracia, muchas son las voces que denuncian el persistente malestar y discriminación de la población femenina. Ante esta realidad, cada vez es más habitual culpar a la cultura, observando a través de los símbolos la resistencia a aceptar la total igualdad en la esencia espiritual de lo masculino y lo femenino. La dificultad para hacer trascender los valores imbricados en la subjetividad femenina, unida a la negación de la autoridad moral de las mujeres por parte de la iglesia, hace sin duda que los símbolos religiosos y sus connotaciones se hayan convertido en objeto de reflexión para las personas convencidas de que el progreso social requiere de la eliminación de todo tipo de discriminación. También la convergencia de aspiraciones, por un lado, feministas, y por otro lado, ecologistas, derivadas de la sensibilidad ante el estado de explotación del planeta, destapa el deseo de un cambio radical en los valores que nos definen como civilización. La representación en términos de poder y jerarquía de las relaciones entre los sexos, y simultáneamente entre lo humano y la naturaleza, conlleva la normalización de la desigualdad social y de la explotación del planeta, de ahí que a través del símbolo de la Diosa o Madre Tierra, se trate de evocar valores hoy necesarios, como el amor, el respeto a lo diferente, la solidaridad y la consideración realista de nuestras relaciones con el mundo.

\section{Referencias bibliográficas}

BACHOFEN, Johann Jacob. El matriarcado. Una investigación sobre la ginecocracia en el mundo antiguo según su naturaleza religiosa y jurídica. Madrid. Akal, 1992.

Bourdieu, Pierre. La dominación masculina. Barcelona. Anagrama, 2000.

CAlvo, Yadira. La canción olvidada. Heredia (Costa Rica). EUNA, 2002.

CLÉMEnt, Catherine y KRISTEVA, Julia. Lo femenino y lo sagrado. Madrid. Cátedra, 2000.

De Beauvorr, Simone. El segundo sexo. Volúmenes I y II. Madrid. Ediciones Cátedra, 2000.

FORCADES I VILA, Teresa. La teología feminista en la historia. Barcelona. Fragmenta Editorial, 2011.

47. IRIGARAY, Luce. Op. cit., p. 23.

Feminismo/s 20, diciembre 2012, pp. 63-80 
Gebara, Ivone. Teología a ritmo de mujer. Madrid. San Pablo, 1995.

Godelier, Maurice. La producción de Grandes Hombres. Poder y dominación masculina entre los Baruya de Nueva Guinea. Madrid. Akal, 1986.

Gómez Acebo, Isabel. (ed.) Mujeres y ¿Sectas? Ayer y hoy. Bilbao. Desclée de Brouwer, 2000.

GÓmez ACEBO, Isabel. Dios en la teología feminista. Estado de la cuestión. <http:// www.ciudaddemujeres.com/articulos/article.php3?id_article $=30>$ [Consulta: 2 de junio de 2012]

GRAVES, Robert. La diosa blanca. Madrid. Alianza Editorial, 1996.

IRIGARAY, Luce. Yo, tú, nosotras. Madrid. Cátedra, 1992.

Kramarae, Cheris y Spender, Dale (eds.). Teologías feministas. Enciclopedia Internacional de las mujeres. Madrid. Síntesis, 2006, pp. 2292-2294.

Kramarae, Cheris y SPender, Dale (eds.). Teología mujerista. Enciclopedia Internacional de las mujeres. Madrid. Síntesis, 2006, pp. 2289-2292.

Kramarae, Cheris y Spender, Dale (eds.). Espiritualidad de la diosa. Enciclopedia Internacional de las mujeres. Madrid. Síntesis, 2006, pp. 823.

LERNER, Gerda. La creación del patriarcado. Barcelona. Crítica, 1990.

LoRENTE ACOSTA, Miguel. Los nuevos hombres nuevos. Los miedos de siempre en tiempos de igualdad. Barcelona. Destino, 2009.

Mediano, Lorenzo. El secreto de la diosa. Barcelona. Random House Mondadori, 2004.

Merchant, Carolyn. «Spiritual Ecology», en Carolyn Merchant. Radical Ecology. New Cork. Chapman \& Hall, 1992, pp. 110-131.

PINTOS, Margarita. «Una tierra que mana leche y miel», en María Luisa Cavana, Alicia Puleo y Cristina Segura (coords.). Mujeres y ecología: historia, pensamiento y sociedad. Madrid. Al-mudayna, pp. 167-172.

REEVES SANDAY, Peggy. «Escritos para el poder femenino», en Aurora Marquina (comp.). El ayer y el hoy: Lecturas de antropología política. Volumen I. hacia el futuro. Madrid. Universidad de Educación a Distancia, 2004.

RodríGuez Blanco, María Eugenia. «Mujeres monstruo o monstruos de mujer en la mitología griega», en Rosario López Gregorio y Luis Unceta Gómez (eds.). Ideas de mujer. Facetas de lo femenino en la Antigüedad. Centro de Estudios sobre la Mujer de la Universidad de Alicante, 2011, pp. 65-91.

UNCETA GÓMEZ, Luis. «De profesión, maga», en Rosario López Gregorio y Luis Unceta Gómez (eds.). Ideas de mujer. Facetas de lo femenino en la Antigüedad. Centro de Estudios sobre la Mujer de la Universidad de Alicante, 2011, pp. 317-341.

VV.AA. Las mujeres en la prehistoria. Valencia. Diputació Provincial de València. Museu de Prehistòria de València, 2006. 